\title{
CONFUCIANISM AS A FORM OF RELIGIOUS NATURALISM
}

\section{Mary Evelyn Tucker}

Confucianism religious naturalism encompasses a dynamic cosmological orientation that is interwoven with spiritual expressions in the form of communitarian ethics of the society, self-cultivation of the person, and ritual expressions integrating self, society, and cosmos. This tapestry of spiritual integration, which has had a long and rich history in China and in other countries of East Asia deserves further study. The author thinks such studies will also point the way toward future forms of Confucian religious naturalism in new and creative expressions.

Keywords: Confucianism, religious naturalism, self-perfection, communitarism, cosmology.

\section{Introduction}

The art of Confucian religious naturalism might be described as discovering one's cosmological being amidst daily affairs. For the Confucian the ordinary is the locus of the extraordinary; the secular is the sacred; the transcendent is in the immanent. What distinguishes Confucianism is an all-encompassing cosmological context that grounds its world-affirming orientation for humanity. This is not a tradition seeking liberation outside the world, but one that affirms the spirituality of becoming more fully human within the world. The way of immanence is the Confucian way. ${ }^{1}$

The means of self-transformation is through cultivation of oneself in relation to others and to the natural world. This cultivation is seen in connection with a tradition of scholarly reflection embedded in a commitment to the value of culture and its myriad expressions. It aims to promote flourishing social relations, effective educational systems, sustainable agricultural patterns, and humane political governance within the context of the dynamic, life-giving processes of the universe.

One may hasten to add that, while subject to debate, aspects of transcendence are not entirely absent in this tradition, for example, in the idea of Heaven in classical Confucianism or the Supreme Ultimate in later Neo-Confucianism. ${ }^{2}$ However, the emphasis of Confucian spirituality is on cultivating one's Heavenly-endowed nature in relation to other humans and to the universe itself. There is no impulse to escape samsara, the cycles of suffering as in Hinduism or Buddhism or to seek other-worldly salvation as in Judaism, Christianity, or Islam. Rather, the microcosm of the self and the macrocosm of the universe are implicitly and explicitly seen as aspects of a unified but ever-changing reality.

The seamless web of immanence and transcendence in this tradition thus creates a unique form of spiritual praxis among the world's religions. There is no ontological split between the supernatural and the natural orders. Indeed, this may be identified as one of the distinctive contributions of Confucianism, both historically and in its modern revived forms.

Journal of Globalization Studies, Vol. 10 No. 1, May 2019 87-96 DOI: $10.30884 / j o g s / 2019.01 .06$ 
How to describe this form of religious naturalism is part of the challenge to give the reader an overview of the remarkable array of Confucian thought from the classical period to the contemporary period. We hope that by examining these distinctive forms of Confucianism the very notion of religious naturalism will be broadened and enriched as a result. It is important to realize that the broad aspirations of Confucianism were not always realized. Indeed, like all pre-modern religious traditions, hierarchical and autocratic aspects often dominated.

\section{What Is Confucian Religious Naturalism?}

Among the world's religious traditions Confucianism has the distinction of being the tradition that is least understood as having religious or spiritual aspects. Part of the complexity of the problem regarding the religious nature of Confucianism lies in sorting out a series of interlocking questions. Foremost among them is how one defines Confucianism - as a political system, as ethical teachings, as social norms, as a humanistic philosophy, or as a religious worldview. ${ }^{3}$ We acknowledge all of these features as being part of Confucianism. However, we aim here to explore Confucianism not necessarily as a 'religion' per se, but as a religious naturalism with distinctive spiritual dimensions.

We are refraining from using the term 'religion' to describe Confucianism because 'religion' tends to be associated with formal institutional structures and most often with characteristics of Western religions such as theism, personal salvation, and natural/ supernatural dichotomies. ${ }^{4}$ The term 'religion' may thus obscure rather than clarify the distinctive religious and spiritual dimensions of Confucian naturalism. ${ }^{5}$ Therefore, instead of claiming Confucianism as a religion (which is problematic in itself for many people), we are suggesting that Confucianism is a religious naturalism with a cosmological orientation. ${ }^{6}$ This cosmological orientation is realized in the connection of the microcosm of the self to the macrocosm of the universe through spiritual practices of communitarian ethics, self-transformation, and ritual relatedness.

Religious naturalism in the Confucian context is that which gives humans a comprehensive and defining orientation to ultimate concerns. Spirituality is that which provides expression for the deep yearnings of the human for relatedness to these ultimate concerns. While a religious worldview may be assumed as part of a given set of cultural ideals and practices into which one is born, spirituality may be seen as the vehicle of attainment of these ideals. Confucian religious naturalism is distinguished by its cosmological context in which humans complete the triad of Heaven and Earth. Confucian spirituality requires discipline and practice along with spontaneity and creativity. Confucian spirituality establishes different ethical responsibilities for specific human relations, deepens subjectivity in its methods of self-cultivation, and celebrates communion of cosmic and human forces in its ritual connections. It aims to situate human creativity amidst concentric circles of interdependent creativity from the person to the larger universe.

One way to appreciate the distinctiveness of Confucian religious naturalism and its spiritual expressions is to observe broad characteristics of religions with a common geographical place of origin. In this spirit it is significant to note that the flowering of the world's religions, which occurred in the sixth century BCE, was labeled by Karl Jaspers as the Axial Age (Jaspers 1953). This period can be characterized as having three major 
centers of origin: those in West Asia - Judaism, Christianity, Islam; those in South Asia Hinduism, Jainism, Buddhism; those in East Asia - Confucianism and Daoism. The first can be described as prophetic and historically-based religions; the second can be seen as mystical religions and religions of liberation; the third can be understood as religious naturalisms of cosmic and social harmony (Berthrong 1994: 216). It is precisely the interaction of the cosmic and social that underlies the spiritual dynamics of Confucian naturalism.

\section{The Appeal of Confucian Religious Naturalism}

As David Keightley observes: 'The strength and endurance of the Confucian tradition, ostensibly secular though its manifestations frequently were, cannot be fully explained, or its true nature understood, unless we take into account the religious commitment which assisted at that tradition's birth and which continued to sustain it' (Keightley 1978: 224). Clearly, Confucian thought had an appeal to individuals and groups in East Asia for centuries beyond its political or ideological uses. Individual scholars and teachers engaged in the study and practice of Confucianism for intellectual inspiration, personal edification, spiritual growth, and ritual expression. We can see this in the spread of Confucianism to Korea, Japan, and Vietnam. This was especially evident in Japan where there was no civil service examination system to advance personal careers. In the Tokugawa period (1603-1868), for example, many Japanese scholars and teachers studied Confucianism for its inherent value and assisted its spread in the society by establishing schools (Rubinger 1982).

Confucianism is more than a conventional stereotype of a model for creating social order and political stability sometimes used for oppressive or autocratic ends. While Confucianism aimed to establish stable and harmonious societies, it also encouraged personal and public reform, along with the reexamination of moral principles and spiritual practices appropriate to different contexts (de Bary 1953). This is evident in Confucian moral and political theory, from the early classical concept of the rectification of names in the Analects to Mencius' qualified notion of the right to revolution. It is likewise seen in the later Neo-Confucian practice of delivering remonstrating lectures to the Emperor and, when necessary, withdrawing one's services from an unresponsive or corrupt government.

On a personal level, the whole process of self-cultivation in Confucian spiritual practice was aimed at achieving authenticity and sincerity through conscientious study, critical self-examination, continual effort, and a willingness to change oneself (de Bary 1991). 'Learning for oneself', not simply absorbing ideas uncritically or trying to impress others, was considered essential to this process (Ibid.). Thus, authenticity could only be realized by constant transformation so as to bring oneself into consonance with the creative and generative powers of Heaven and Earth (Tu Weiming 1989). These teachings sought to inculcate a process in tune with the dynamic, cosmological workings of nature. It thus affirmed change as a positive force in the natural order and in human affairs. This process of harmonizing with changes in the universe can be identified as a major wellspring of Confucian spirituality expressed in various forms of selfcultivation. This is at the heart of Confucian religious naturalism. 
The focus on the positive aspects of change can be seen in each period of Confucianism as well as in its spread to other geographical contexts. Change in self, society, and cosmos was affirmed and celebrated from the early formative period, which produced the Classic of Changes (Yi Ching). Later Han Confucianism emphasized the vitality of correspondences between the human and the various elements in nature. ${ }^{7}$ Eleventh and twelfth century Sung Neo-Confucianism stressed the creativity of Heaven and Earth. Confucian spirituality in all its diverse expressions was seen in East Asia as a powerful means of personal transformation. Furthermore, it was a potential instrument of establishing social harmony and political order through communitarian ethics and ritual practices. It emphasized moral transformation that rippled outward across concentric circles rather than the external imposition of legalistic and bureaucratic restraints. It was precisely this point that differentiated the Confucian aspirations and ideals from those of the Legalists, such as Han Fei Zi, who felt that humans could be restrained by law and changed by punishment. ${ }^{8}$ Confucianism is a tradition that has endured for more than two and half millennia in varied historical, geographical, and cultural contexts. It is still undergoing transformation and revitalization in its contemporary forms. ${ }^{9}$

\section{Overview of the Historical Development of Confucianism}

The Confucian tradition has assumed distinctive expressions in China, Korea, Japan, Vietnam, Hong Kong, Taiwan, and Singapore. Viewing Confucianism as a singular tradition is problematic because of its geographic spread, its historical development, and its varied forms, ranging from Imperial State Confucianism to local and familial Confucianism. Nonetheless, this overview will try to make some distinctions in the various kinds of Confucianism in order to highlight aspects of its religious naturalism. ${ }^{10}$

While originating in the first millennium BCE in China, the tradition includes the transmission and transformation of Confucianism that took place in different East Asian cultural and geographical contexts. In examining the reasons for its spread and its appeal, it is important to highlight the ways in which it interacted with native traditions in China and across East Asia. Confucianism, for example, responded to and mingled with Daoism and Buddhism in China, with shamanism in Korea, and with Shinto in Japan. ${ }^{11}$ The borrowing and creative interaction among the various religious traditions in East Asia needs to be underscored. Indeed, the so-called unity and syncretism of the three traditions of Confucianism, Daoism, and Buddhism in China should be noted. This was especially pronounced in the Ming (1368-1644) and Qing (1644-1911) periods (Berling 1980).

While recognizing this dynamic cross fertilization of religious traditions in East Asia, we can also identify historically four major periods of Confucian thought and practice. The first stage in China is that of classical Confucianism, which ranges from approximately the sixth to the second century BCE. This is the period of the flourishing of the early Confucian thinkers, namely Confucius and Mencius. The second period is that of Han Confucianism when the classical tradition was shaped into a political orthodoxy under the Han Empire (202 BCE-220 CE) and began to spread to other parts of East Asia. This period saw the development of the theory of correspondences of the microcosm of the human world with the macrocosm of the natural world. The third major period is the Neo-Confucian era from the eleventh to the early twentieth century. 
This includes the comprehensive synthesis of Zhu Xi in the eleventh century and the distinctive contributions of Wang Yangming in the fifteenth and sixteenth centuries. The influence of Confucianism as an educational and philosophical system was felt throughout many parts of East Asia during this period. The last phase is that of New Confucianism in the twentieth century, which represents a revival of the tradition under the influence of scholars who came to Taiwan and Hong Kong after Mao's ascendancy in 1949. ${ }^{12}$ Four decades later, in October 1989, the International Confucian Society held two major conferences in Beijing and in Confucius' birthplace, Qufu, to explore the future of the Confucian Way. These conferences were intended to mark the $2540^{\text {th }}$ anniversary of Confucius' birth and they both signified the interest of Confucian practitioners in looking toward the future.

\section{Worldview and Ethos: Organic Cosmology and Communitarian Ethics}

Confucian religious naturalism, while by no means singular or uniform, is the one that can be described as having an organismic cosmology (Needham 1956: 291-293) characterized as a 'continuity of being' (Tu Weiming 1985) within an 'immanental cosmos'. ${ }^{13}$ There is no clear separation, as in the Western religions, between a transcendent, other-worldly order and an immanent, this-worldly orientation. As the Mean (Zhongyong) states: 'The Way of Heaven and Earth can be described in one sentence: They are without any doubleness and so they produce things in an unfathomable way. The Way of Heaven and Earth is extensive, deep, high, brilliant, infinite, and lasting' ${ }^{14}$

Without an ontological gap between this world and another world there emerges an appreciation for the seamless interaction of humans with the universe. The Confucian cosmological worldview is one that embraces a fluid and dynamic continuity of being. In terms of ethos or ethics this involves working out the deep interconnections of Heaven, Earth, and humans. This profound symbolic expression of the triadic intercommunion of an immanental cosmos is invoked repeatedly in both the Confucian and NeoConfucian texts cited across East Asia. ${ }^{15}$ As Tu Weiming notes, this cosmology is neither theocentric nor anthropocentric, but rather anthropo-cosmic (1989: 102-107). In this sense the emphasis is not exclusively on the divine nor on humans, as is the prevailing model in the west. Rather, the comprehensive interaction of Heaven, Earth, and humans is what is underscored by the term anthropocosmic. Thus the worldview of an organic cosmology creates a context for the intricate communitarian model of social ethics that distinguishes East Asian societies.

The mutual attraction of things for one another in both the human and natural worlds gives rise to an embedded ethical system of reciprocal relationships. The instinctive qualities of the human heart toward commiseration and empathy is what is nurtured and expressed in human relations and ritual practices (Mencius 2A:6). The human is not an isolated individual in need of redemption by a personal God, but is deeply embedded in a network of life-giving and life-sustaining relationships and rituals. Within this organic universe the human is viewed as a microcosm of the macrocosm where one's actions affect the larger whole, like ripples in a pond as expressed in the Great Learning. Thus, there is a relational resonance of personal and cosmic communion animated by authenticity (cheng) as illustrated in the Mean (see de Bary and Bloom 1999: Chs. 22, 
$25,26)$. The individual is intrinsically linked via rituals to various communities, beginning with the natural bonding of the family and stretching out to include the socialpolitical order and embracing the symbolic community of Heaven and Earth (Berry 2003). Humans achieve their fullest identity as members of the great triad with Heaven and Earth. Within this triad Heaven is a guiding moral presence, Earth is a vital moral force, and humans are co-creators of a humane and moral social-political order.

\section{Cosmology and Cultivation: Creativity of Heaven and Transformation of Humans}

Confucian religious naturalism embraces a vast cosmological order that is distinguished by the creativity of Heaven as a life-giving force that is ceaselessly self-generating (Book of Changes Appendix HI 2:1/8. See also the chapter on 'Creative Principle' in H. Wilhelm 1977). ${ }^{16}$ Similar to Whiteheadian process thought, the Confucian universe is seen as an unfolding, creative process, not as a static, inert mechanistic system controlled by an absent or remote deity (Berthrong 1994). As a protecting, sustaining and transforming force, Heaven helps to bring all to their natural fulfillment as cosmological. This is because humans are imprinted with a Heavenly-endowed nature, which enables them to transform themselves through self-cultivation (see the Mean, Ch. 1 in de Bary and Bloom 1999).

The ethos, then, of this creative cosmology is one that encourages education, learning, and self-transformation. The optimistic view of humans as receiving a Heavenly nature results in a Confucian educational and family ethos, which ideally creates a value system for nurturing innate human goodness and the creative transformation of individual potential. This ethos is one that encourages a filial sense of repayment to Heaven for the gift of life and for a Heavenly-bestowed nature. The way to repay these gifts is through ongoing moral cultivation for the betterment of self and society. The symbol or model which joins this aspect of the worldview and ethos together is the noble person (junzi), or the sage (sheng), who 'hears' the will of Heaven and is able to embody it naturally in the ongoing process of learning and self-cultivation. The sage is thus the highest embodiment of the spiritual aspirations of the Confucian tradition (Taylor 1990).

\section{Vitalism of the Earth and Co-creativity of Humans: Cosmological Correspondences and Human Ritual}

The creativity of Heaven in the Confucian cosmological worldview is paralleled by the vitalism of the natural world. From the early text of the Classic of Changes (Yiiing), through the Neo-Confucian re-appropriation of this classic, the sense of the vitality of the natural world infuses many of the Confucian writings (Smith et al. 1990). This vitality is understood as part of the seasonal cycles of nature, rather than as the developmental, evolving universe discussed by contemporary process philosophers and theologians. It is expressed in an elaborate series of correspondences (seasonal, directional, elemental) which in Han Confucianism were seen as patterns suggestive of the careful regulation needed in the social and political realms (Rosemont 1984; Queen 1996; Eno 1990; Henderson 1984). This cosmological view of the integral cycles of nature reinforces an ethos of cooperating with those processes through establishing a harmonious 
society and government with appropriate ritual structures. The rituals reflect the patterned structures of the natural world and bind humans to one another, to the ancestral world, and to the cosmos at large.

The vital material force ( $q$ i) of the universe is that which joins humans and nature, unifying their worldview and ethos and giving humans the potential to become cocreators with the universe (Tu Weiming 1989: 70, 78, 98, 102, 106). As Mencius notes, it is $q i$ that unites rightness (ethos) and the Way (worldview), filling the whole space between Heaven and Earth (Mencius 2A:2). The moral imperative of Confucianism, then, is to make appropriate ethical and ritual choices linked to the creative powers of the Way and thus contribute to the betterment of social and political order.

Confucian religious naturalism, then, affirms change, as is manifest in the creativity of Heaven and in the vitality of Earth. In particular, the varied and dynamic patterns of cosmological change are celebrated as part of a life-giving universe. Rituals and music are designed to harmonize with these cosmic changes and to assist the process of personal transformation. Rituals help to join the worldview of cosmic change with the ethos of human changes in society, thus harmonizing the natural and human orders. Rituals and music are a means of creating grace, beauty, and accord. Thus, the natural cosmological structures of the Earth provide a counterpoint for an ethos of social patterns expressed in ritual behavior and music. Harmonizing with the universe in a cosmological sense is balanced by an ethos of reciprocal resonance in human relations and expressed in the patterned behavior of rituals.

\section{Conclusion}

Confucianism religious naturalism encompasses a dynamic cosmological orientation that is interwoven with spiritual expressions in the form of communitarian ethics of the society, self-cultivation of the person, and ritual expressions integrating self, society, and cosmos. This tapestry of spiritual integration, which has had a long and rich history in China and in other countries of East Asia deserves further study. We trust such studies will also point the way toward future forms of Confucian religious naturalism in new and creative expressions.

\section{NOTES}

\footnotetext{
${ }^{1}$ In this paper, except where noted, we are using the term Confucian and Confucianism to refer to the tradition in a broad sense without necessarily distinguishing between the early classical Confucian expressions and the later Neo-Confucian forms in China, Korea, and Japan.

${ }^{2}$ As Tu Weiming puts it, 'Despite the difficulty of conceptualizing transcendence as radical otherness, the Confucian commitment to ultimate self-transformation necessarily involves a transcendent dimension' (1985: 137). This is not 'radical transcendence but immanence with a transcendent dimension' (Idem 1989: 121). See similar arguments made earlier by Liu Shu-hsien, 'The Confucian Approach to the Problem of Transcendence and Immanence' (1972). Roger Ames and David Hall have argued that the Confucian tradition, especially in its classical forms does not focus on transcendence (see Ames and Hall 1987, 1998; see also Ames 1984).

${ }^{3}$ Liu Shu-shien and others have observed that Confucianism as a cultural ideal embodying certain spiritual values and aspirations should be differentiated from Confucianism as embedded in social and political ideologies and institutions. See his chapter in Tu Weiming 1996; see also Liu Shu-sien 1998).
} 
${ }^{4}$ While one could utilize certain western definitions of religion to illustrate that Confucianism is a religion, these definitions may limit the understanding of the nature of Confucian spirituality. For example, we can draw on both Paul Tillich's and Frederick Streng's definitions of religion. For Tillich, religion focuses on ultimate concern, while Streng suggests that religion is a means of ultimate transformation (see Tillich 1952, and Streng 1985).

Both of these broad definitions are applicable to Confucianism. Ultimate concern in Confucianism is evident when a person is responding to the will of Heaven that is discovered in one's Heavenlyendowed nature and manifest in temporal affairs. Ultimate transformation in Confucianism involves modes of self-cultivation, which are intellectual, spiritual, and moral. The goal here is to become more fully human, namely, more deeply empathetic and more comprehensively compassionate. Ultimate transformation leads one toward sagehood. Still, this attainment is within the phenomenal world, not apart from it, and for the benefit of the larger society, not for one's salvation alone. This distinguishes Confucian religiosity from western forms of religion (see also Smith 1963) for a discussion of the nature of religion.

Articulating the Confucian worldview (both philosophically and religiously) apart from western categories has been the concern of Roger Ames and David Hall who suggest that Confucianism is at once non-theistic and profoundly religious. See their commentary on the Mean in Focusing the Familiar (2001).

${ }^{5}$ Tu Weiming has observed: 'The problem of whether Neo-Confucianism is a religion should not be confused with the more significant question: what does it mean to be religious in the NeoConfucian community? The solution to the former often depends on the particular interpretive position we choose to take on what constitutes the paradigmatic example of a religion, which may have little to do with our knowledge about Neo-Confucianism as a spiritual tradition...' (Tu Weiming 1985: 132).

${ }^{6}$ I am indebted to the work of Wm. Theodore de Bary and Tu Weiming in this area. For one of the first comprehensive discussions of the religious dimensions of Confucianism see de Bary's introduction to The Unfolding of Neo-Confucianism (1975). Similarly see Tu Weiming (1989). In addition, the work of P. J. Ivanhoe and R. Ames and D. Hall has been significant. See Ivanhoe (2000), and Ames and Hall's numerous books including their most recent, Focusing the Familiar (2001).

${ }^{7}$ It is important to note that this ordering of cosmos and society can have both life-enhancing and life-constraining dimensions. When used as political ideology in the Han period the record becomes more mixed.

${ }^{8}$ The Confucians were, however, caught in matters of pragmatic politics of governance that often required not only an appeal to personal moral transformation and ritual practice as a means of restraint, but also recognized that law and punishment had their function, although as a secondary measure.

${ }^{9}$ Many of the writings of western Confucian scholars are being translated into Chinese as part of the renewed interest in Confucianism in China. These include works by Wm. Theodore de Bary, Tu Weiming, Roger Ames and David Hall, Robert Neville, John Berthrong and two volumes on Confucian Spirituality edited by Tu Weiming and Mary Evelyn Tucker.

${ }^{10}$ Clearly the tension of acknowledging the historical particularity of Confucianism along with identifying certain overarching religious elements in the tradition is present here.

${ }^{11}$ For example, in Japan Confucianism linked itself to Shinto during the $17^{\text {th }}$ century, was separated from it by the nativists of the $18^{\text {th }}$ century, and was rejoined to Shinto again in the late $19^{\text {th }}$ century. Japanese Confucianism as a worldview and as a form of spiritual cultivation is still part of many of the New Religions in Japan and deserves further study. See Helen Hardacre's discussion of 'The World View of the New Religions' in Kurozumikyo and the New Religions of Japan (Hardacre 1986: Ch. 1).

${ }^{12}$ Tu Weiming speaks of the New Confucians as the 'Third Epoch of Confucian Humanism' after the classical and Neo-Confucian periods (Eber 1986: 3-21). John Berthrong has outlined six periods of Confucianism which separate out the Han, Tang, and later Qing Evidential Learning (see Berthrong 1994: 77-83; 191-192).

${ }^{13}$ This is a term used by Roger Ames and David Hall (1987): 12-17.

${ }^{14}$ Translated by Wing-tsit Chan (1963: 109). 
15 These include, among others, the Book of Changes (Third Appendix), the Book of Ritual ( th $^{\text {th }}$ Chapter), the Mean (Chapter 22), Dong Zhongshu, Luxuriant Gems of the Spring and Autumn Annals (Chapter 44), the Diagram of the Great Ultimate of Zhou Dunyi, the Western Inscription of Zhang Zai, the Commentary on the Great Learning by Wang Yangming (see these texts in de Bary, Wm, and Bloom 1999).

${ }^{16}$ The NeoConfucians frequently refer to the productive and reproductive forces of the universe (Ch. sheng sheng, Jp. sei sei).

\section{REFERENCES}

Ames, R. 1984. Religiousness in Classical Confucianism: A Comparative Analysis. Asian Culture Quarterly 12 (2): 7-23.

Ames, R., and Hall, D. 1987._Thinking through Confucius. Albany, N.Y.: State University of New York.

Ames, R., and Hall, D. 2001. Focusing the Familiar. Albany, N.Y.: State University of New York.

de Bary, Wm. T. 1953. A Reappraisal of Neo-Confucianism. In A. Wright (ed.), Studies in Chinese Thought. The American Anthropological Association 55 (5). Part 2 Memoir No. 75 (December).

de Bary, Wm. T. (Ed.) 1975. The Unfolding of Neo-Confucianism. New York: Columbia University Press.

de Bary, Wm. T. 1991. Learning for One's Self. New York: Columbia University Press.

de Bary, Wm. T., and Bloom, I. (eds.) 1999. The Sources of Chinese Tradition. New York: Columbia University Press.

Berling, J. 1980. The Syncretic Religion of Lin Chao-en. New York: Columbia University Press.

Berry, T. 2003. Affectivity in Classical Confucian Tradition. In Weiming, T., and Tucker, M. E. (eds.), Confucian Spirituality (pp. 1-96). Crossroad Pub. Company.

Berthrong, J. 1994. All Under Heaven: Transforming Paradigms in Confucian-Christian Dialogue Albany, N.Y.: State University of New York.

Eber, I. (ed.) 1986. Confucianism: The Dynamics of Tradition. New York: Macmillan.

Eno, R. 1990._The Confucian Creation of Heaven. Albany, N.Y.: State University of New York.

Hall, D. L., and Ames, R. T. 1998. Thinking from the Han: Self, Truth and Transcendence in Chinese and Western Culture. Albany, N.Y.: State University of New York.

Hardacre, H. 1986. The World View of the New Religions. Kurozumikyo and the New Religions of Japan. Princeton: Princeton University Press.

Henderson, J. 1984. The Development and Decline of Chinese Cosmology. New York: Columbia University Press.

Ivanhoe, P. J. 2000. Confucian Moral Self Cultivation. Indianapolis: Hackett.

Jaspers, K. 1953. Origin and Goal of History. London: Routledge and K. Paul.

Keightley, D. 1978. The Religious Commitment: Shang Theology and the Genesis of Chinese Political Culture. History of Religions 17 (3/4): 211-225. doi:10.1086/462791.

Liu Shu-hsien 1972. The Confucian Approach to the Problem of Transcendence and Immanence. Philosophy East and West 22 (1): 45-52. 
Liu Shu-hsien 1998. Understanding Confucian Philosophy: Classical and Sung-Ming. Westport, CT.: Praeger.

Needham, J. 1956. Civilization in China. Vol. 2. Cambridge: Cambridge University Press.

Queen, S. 1996. From Chronicle to Canon: The Hermeneutics of the Spring and Autumn according to Tung Chung-shu. New York: Cambridge University Press.

Rosemont, H. (ed.) 1984. Explorations in Early Chinese Cosmology. Chico, CA: Scholars Press.

Rubinger, R. 1982. Private Academies of Tokugawa Japan. Princeton: Princeton University Press.

Smith, W. C. 1963. The Meaning and End of Religion. New York: Macmillan.

Smith, K., Bol, P., Adler, J., and Wyatt, D. 1990. Sung Dynasty Uses of the I Ching._Princeton: Princeton University Press.

Streng, F. 1985. Understanding Religious Life. Belmont, CA.: Wadsworth Publishing Co.

Taylor, R. 1990. The Religious Dimensions of Confucianism. Albany, N.Y.: State University of New York.

Tillich, P. 1952. The Courage to Be. New Heaven: Yale University Press.

Tillich, P. 1957. The Dynamics of Faith. New York: Harper and Row.

Tu Weiming 1985. Confucian Thought: Selfhood as Creative Transformation. Albany, N.Y.: State University of New York.

Tu Weiming 1989. Centrality and Commonality: An Essay on Confucian Religiousness. Albany, N.Y.: State University of New York.

Tu Weiming 1989. Centrality and Commonality. Albany, N.Y.: State University of New York.

Tu Weiming 1996. Confucian Traditions in East Asian Modernity: Moral Education and Economic Culture in Japan and the Four Mini Dragons. Cambridge, MA: Harvard University Press.

Wilhelm, H. 1977. Creative Principle. Heaven, Earth and Man in the Book of Changes. Seattle: University of Washington Press.

Wing-tsit Chan 1963. A Source Book in Chinese Philosophy. Princeton: Princeton University Press. 